\title{
Does prone positioning improve oxygenation and reduce mortality in patients with acute respiratory distress syndrome?
}

\author{
William R Henderson MD ${ }^{1,2}$, Donald EG Griesdale MD MPH ${ }^{1,3}$, Paolo Dominelli MSc², Juan J Ronco MD ${ }^{1}$
}

\begin{abstract}
A cute respiratory distress syndrome (ARDS) is defined as the acute onset of bilateral chest infiltrates with impaired oxygenation that is not explained by cardiac failure or fluid overload $(1,2)$. ARDS is characterized by alterations in pulmonary mechanics, ventilation and perfusion $(\mathrm{V} / \mathrm{Q})$ mismatch and severe hypoxemic respiratory failure (3). The most frequently cited precipitating events for ARDS are sepsis, pneumonia, aspiration, trauma, pancreatitis and blood transfusions (2-5). Current estimates of mortality associated with ARDS range from to $22 \%$ to $44 \%(6-8)$.

With the increased use of computed tomography imaging in the mid-1980s, it became evident that ARDS was characterized by areas of relatively normal lung parenchyma juxtaposed with areas of dense consolidation and atelectasis (9). In supine patients, the dorsal regions of the lung are susceptible to profound lung derecruitment due to increases in parenchymal edema. ARDS patients are at high risk for developing ventilator-associated lung injury (VALI) due to abnormally high localized parenchymal strain due to the regional heterogeneity of lung consolidation and inflammation (10). While the use of low tidal volumes during mechanical ventilation for lung injury has led to improved clinical outcomes, presumably from decreased VALI associated with alveolar distension and trauma (11), it has not improved the severe atelectasis, consolidation, shunt and hypoxia associated with ARDS. More recently, the use of high levels of positive end-expiratory pressure to improve shunt and hypoxia in ARDS has met with mixed results (12). Recognition that the heterogeneous atelectasis and consolidation seen in ARDS is often dorsally distributed led investigators to question whether care for patients with ARDS in the prone - as opposed to the supine - position may lead to improved mortality outcomes. The present clinical review provides an overview of the physiological rationale for, and the clinical evidence related to, prone positioning's effects on oxygenation and mortality in ARDS.
\end{abstract}

\section{ANATOMICAL AND PHYSIOLOGICAL CONSEQUENCES OF PRONE VENTILATION}

During prone positioning, ventilation is improved due to changes in pleural pressure $\left(\mathrm{PPL}_{\mathrm{PL}}\right.$ and the amount of lung atelectasis present. PPL is the sum of all forces acting to compress the alveolus and includes the weight of tissue above the alveolus and the transmitted pressure across the diaphragm from the abdomen. Simplistically, an alveolus will remain open when the intra-alveolar pressure exceeds PPL. When a patient with ARDS is placed prone, the dorsal lung is no longer subject to high Pru and dorsal lung atelectasis decreases. Conversely, the ventral lung units are exposed to a higher PpL and are more likely to collapse. This 'sponge model' was first described by Gattinoni et al (13) and provides a satisfying explanation for the rapid radiographic changes in the distribution of atelectasis apparent with prone positioning in ARDS. If we assume that the lungs are symmetrical, then the amount of lung tissue subject to atelectasis is the same in both the prone and supine positions, and the degree of shunt and hypoxia will not vary between the two positions if blood flow is unchanged

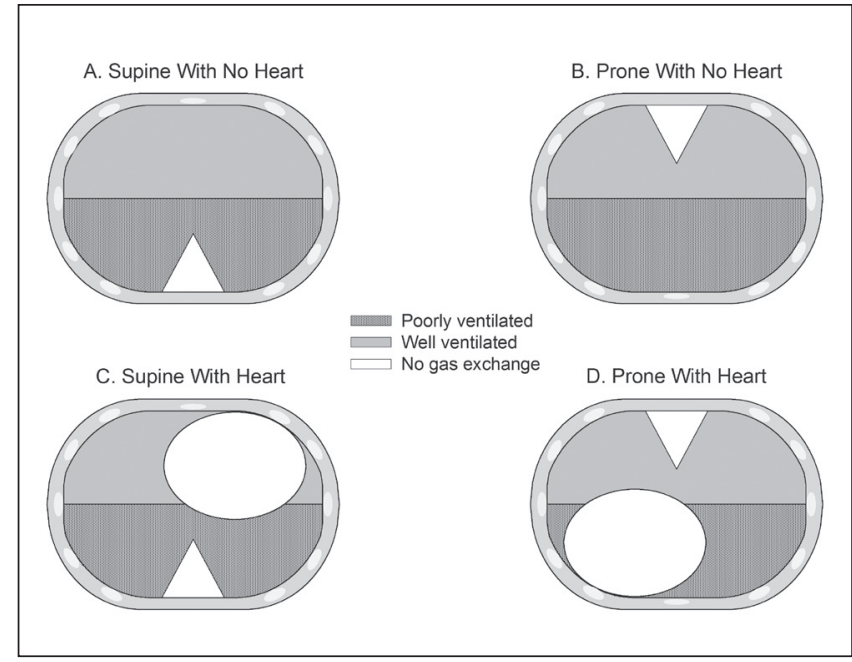

Figure 1) Schematic representation of changes in the volume of ventilated lung between the supine and prone positions. The vertebral column and associated structures is represented by the white triangle while the heart and associated structures is represented by the white oval. In a chest cavity containing symmetrical lungs, the amount of lung that is well ventilated (where the alveolar pressure exceeds the pleural pressure) roughly equals the amount of lung that is atelectatic and poorly ventilated (where pleural pressure exceeds intra-alveolar pressure) in both supine and prone positions (A and B). However, when the space occupied by the mediastinum and heart are accounted for, and the effects of the compression of lung tissue subjacent to these structures are considered, there is less ventilated tissue in the supine position (C) than in the prone position (D). Effects of the transmitted abdominal pressure on the caudal posterior lung are not reflected in this diagram

(Figures 1A and 1B). However, the lungs are not symmetrical between the two positions due to both the position of the heart (and other ventral intrathoracic structures) and its compression of the subjacent lung parenchyma. Furthermore, in patients who have lost diaphragmatic tone (due to sedation or paralysis), abdominal contents displace the diaphragm caudally, causing compression of the posteriorcaudal lung parenchyma (14). All of these factors are reversed in the prone position, creating a situation in which more recruited lung is available in the prone position than in the supine position (Figures $1 \mathrm{C}$ and 1D) and the vertical gradient of PpL is decreased. Given that the distribution of pulmonary blood flow is relatively homogenous in ARDS and does not vary significantly between prone and supine positioning, V/Q matching and thus, oxygenation, is improved in the prone compared with the supine position.

${ }^{1}$ Division of Critical Care Medicine, Department of Medicine; ${ }^{2}$ School of Kinesiology; ${ }^{3}$ Department of Anesthesiology, Pharmacology and

Therapeutics, Faculty of Medicine, University of British Columbia, Vancouver, British Columbia

Correspondence: Dr William Henderson, Critical Care Medicine, Vancouver General Hospital, ICU2, JPPN 2nd Floor,

Room 2438, 855 West 12th Avenue, Vancouver, British Columbia V5Z 1M9. Telephone 604-875-5949, fax 604-875-5957,

e-mail william.henderson@vch.ca 
TABLE 1

Selected baseline characteristics, within trial mechanical ventilation parameters and mortality of included trials investigating prone positioning

\begin{tabular}{|c|c|c|c|c|c|c|c|c|c|c|c|c|}
\hline \multirow{2}{*}{$\begin{array}{l}\text { First author } \\
\text { (reference), year }\end{array}$} & \multicolumn{2}{|c|}{ Patients, n } & \multicolumn{2}{|c|}{$\begin{array}{c}\mathrm{PaO}_{2} / \mathrm{FiO}_{2} \text { at baseline }{ }^{*}, \\
\mathrm{mmHg}\end{array}$} & \multicolumn{2}{|c|}{$\begin{array}{c}\text { Tidal volume } \\
\text { during trial* }, \mathrm{mL} / \mathrm{kg}\end{array}$} & \multicolumn{2}{|c|}{$\begin{array}{l}\text { PEEP during trial*, } \\
\mathrm{cmH}_{2} \mathrm{O}\end{array}$} & \multirow{2}{*}{$\begin{array}{c}\text { Duration } \\
\text { of prone*, } \\
\text { h }\end{array}$} & \multicolumn{2}{|c|}{ Mortality ${ }^{\dagger}, \%$} & \multirow{2}{*}{$\begin{array}{c}\mathbf{P} \text { for } \\
\text { mortality }\end{array}$} \\
\hline & $\mathbf{P}$ & $\mathrm{S}$ & $\mathbf{P}$ & $\mathrm{S}$ & $\mathbf{P}$ & $\mathrm{S}$ & $\mathbf{P}$ & $\mathrm{S}$ & & $P$ & $\mathrm{~s}$ & \\
\hline Gattinoni (29), 2001 & 152 & 152 & $85.7 \pm 24.6$ & $88.3 \pm 25.9$ & $10.3 \pm 2.7$ & $10.3 \pm 2.9$ & $9.7 \pm 2.9$ & $9.6 \pm 3.2$ & 7 & 21.1 & 25.0 & NS \\
\hline Guérin (18), 2004 & 413 & 378 & $150 \pm 59$ & $155 \pm 59$ & $8.1 \pm 2.0$ & $8.1 \pm 1.9$ & $7.9 \pm 3.4$ & $7.5 \pm 3.2$ & 8 & 31.5 & 32.4 & NS \\
\hline Mancebo (17), 2006 & 76 & 60 & $107 \pm 65$ & $126 \pm 94$ & $8.3 \pm 1.7$ & $8.6 \pm 1.6$ & $12.4 \pm 1.9$ & $12.3 \pm 2.4$ & 17 & 43 & 58 & NS \\
\hline Chan (19), 2007 & 11 & 11 & $111 \pm 62$ & $107 \pm 81$ & $7.8 \pm 1.0$ & $7.6 \pm 1.2$ & $13.1 \pm 1.5$ & $13.6 \pm 2.3$ & 72 & 36.4 & 36.4 & NS \\
\hline Fernandez (20), 2008 & 21 & 19 & $113 \pm 43$ & $122 \pm 40$ & $8.6 \pm 2.1$ & $9.2 \pm 2.2$ & $11.1 \pm 4.1$ & $11.4 \pm 3.8$ & NR & 38.0 & 53.0 & NS \\
\hline Taccone (16), 2009 & 168 & 174 & $113 \pm 39 \ddagger$ & - & $8.0 \pm 1.7$ & - & $10 \pm 3$ & - & 18 & 31 & 32.8 & NS \\
\hline Guérin (30), 2013 & 237 & 229 & $100 \pm 30$ & $100 \pm 20$ & $6.1 \pm 0.6$ & $6.1 \pm 0.6$ & $10 \pm 3$ & $10 \pm 4$ & 17 & 16 & 32.8 & $<0.001$ \\
\hline
\end{tabular}

${ }^{*}$ All values reported separately for prone $(P)$ and supine $(S)$ groups, and as mean $\pm S D$ where data were available. Where separate group values are not shown, values reflect the mean of both $P$ and $S$ groups; ${ }^{\dagger}$ Mortality rates and $P$ values reported for primary outcome measure in each study; $¥$ Values not reported separately for $P$ and $S$ groups. FiO $\mathrm{F}_{2}$ Fraction of inspired oxygen; NR Not reported; NS Not significant; PaO ${ }_{2}$ Partial pressure of oxygen; PEEP Positive end-expiratory pressure

\section{TABLE 2 \\ Patient- and disease-specific factors that increase the probability of improved oxygenation with initiation of prone ventilation}

Empirical
$>10 \mathrm{mmHg}$ increase in $\mathrm{PaO}_{2}$ within 30 min of initiation of prone positioning
Pulmonary mechanical
Increased intra-abdominal pressure (34)
Lower chest wall compliance in prone compared with supine position (22)
Disease specific
Dependent alveolar collapse and diffuse pulmonary edema (35)
Extrapulmonary rather than pulmonary cause of ARDS (36)

ARDS Acute respiratory distress syndrome; $\mathrm{PaO}_{2}$ Partial pressure of oxygen

\section{EFFECT OF PRONE POSITIONING ON OXYGENATION IN ARDS}

To date, seven randomized trials investigating the effects of prone positioning on both oxygenation and mortality in adult ARDS have been reported in the peer-reviewed literature (Table 1). While all trials demonstrated improvements in oxygenation with prone positioning, there was no statistical difference in mortality in six of the seven trials (15-20). The oxygenation benefits of prone ventilation were apparent with the first session in most trials, and the difference in oxygenation between the prone and supine groups tended to increase with the number of sessions. Improvements in oxygenation were often preserved after returning to the supine position (suggesting that once alveoli have reopened, they are more likely to stay open) $(21,22)$. In addition to its effects on alveolar recruitment and strain, prone positioning may promote pulmonary secretion drainage in patients. There is evidence that specific disease and patient characteristics may predict which patients are most likely to show improved oxygenation with prone ventilation (Table 2).

\section{EFFECT OF PRONE POSITIONING ON MORTALITY IN ARDS}

The improvements in oxygenation apparent in most trials investigating prone positioning were not associated with improvements in mortality, suggesting that oxygenation is not itself the source of improved survival with prone positioning. In fact, previous trials investigating mechanical ventilation have demonstrated a poor association between increases in oxygenation and improved mortality (23). Rather, the prone position decreases regional lung parenchymal heterogeneity and, thereby, decreases the likelihood of extreme tissue strain (24), a precipitant of VALI (10). Decreases in regional tissue strain with prone versus supine positioning have been demonstrated empirically (25), and the use of prone positioning has been associated with less regional lung overdistension, decreased production of inflammatory cytokines and improved lung histology in human and experimental models (26-28). If decreased lung strain (with reductions in the development of VALI) is the source of prone positioning's benefit, it becomes easier to understand why the majority of trials investigating prone positioning have failed to demonstrate a mortality benefit.

For example, most trials investigating prone positioning used tidal volumes that would be considered potentially injurious in ARDS according to current standards. In these trials, the benefit of prone positioning on VALI reduction may have been obscured by the effects of a ventilation strategy that amplified lung strain. In two trials, the duration of prone position sessions was $7 \mathrm{~h}$ to $8 \mathrm{~h}(18,29)$, potentially providing too brief a respite from exposure to high lung strain to mitigate the risk of VALI. Moreover, the majority of trials occurred during a period when global mortality from ARDS was decreasing and used varying inclusion criteria, which may have led to the trials being statistically underpowered to detect a mortality benefit from prone positioning. Therefore, to demonstrate a benefit of prone positioning, it would be necessary to perform an adequately powered trial using lung protective ventilation in both the control and intervention arms and prone sessions of significant duration. The Proning Severe ARDS Patients (PROSEVA) study randomly assigned 466 patients with ARDS and an average partial pressure of oxygen $\left(\mathrm{PaO}_{2}\right) /$ fraction of inspired oxygen $\left(\mathrm{FiO}_{2}\right)$ ratio of $100 \mathrm{mmHg}$ to either supine or prone positioning, used low tidal volumes in both groups and achieved long periods of prone positioning in the intervention group (Table 1) (30). This trial by Guérin et al (30) demonstrated that prone ventilation resulted in an absolute risk reduction in 28-day mortality of $16.7 \%$ (95\% CI 9.1\% to $24.4 \%$; $<<0.001$ ). This mortality benefit persisted at 90 days (absolute risk reduction $17.4 \%$ [95\% CI 9.1\% to $25.5 \%$ ]; $\mathrm{P}<0.001$ ). While the PROSEVA trial represents high-quality data on the use of prone positioning in ARDS, several trial features warrant attention. The use of extensive exclusion criteria, the differences in the initial severity of illness and vasopressor use between the supine and the prone group, and the high rate of cardiac arrests in the supine positioning group (31 patients) versus the prone group (16 patients) may limit the external validity of this study.

\section{COMPLICATIONS AND CONTRAINDICATIONS ASSOCIATED WITH PRONE POSITIONING}

While patient-specific factors may help select individuals most likely to benefit from prone positioning during mechanical ventilation (Table 2), several potential complications and contraindications exist. Prone positioning may worsen effective chest wall compliance, potentially decreasing delivered tidal volumes or increasing ventilating pressures (31). Complications, such as airway obstruction and endotracheal tube dislodgement, hypotension and arrhythmias, loss of 
venous access, facial and airway edema, and a greater need for paralysis or sedation, have all been associated with prone positioning with varying frequency $(16,32,33)$. It is unclear whether this increased rate of complications is due to prone positioning per se, or due to a lack of familiarity with the procedure among the surveyed providers. In the PROSEVA trial (whose practitioners were experienced with prone positioning), there was no difference in the rate of most complications between the supine and prone groups, suggesting that it is a safe procedure in the hands of experienced clinicians. Despite prone positioning's potential applicability in ARDS, care must be exercised with its use in patients with hemodynamic instability, facial or ocular injuries, and recent sternotomy or abdominal incisions. Finally, unstable vertebral fractures and significantly increased intracranial pressures are frequently regarded as absolute contraindications to this procedure.

\section{REFERENCES}

1. Bernard GR, Artigas A, Brigham KL, et al; Consensus Committee. Report of the American-European Consensus Conference on the Acute Respiratory Distress Syndrome. J Crit Care 1994;9:72-8.

2. Ranieri VM, Rubenfeld GD, Thompson BT, et al. Acute respiratory distress syndrome: The Berlin definition. JAMA 2012;307:2526-33.

3. Piantadosi CA, Schwartz DA. The acute respiratory distress syndrome. Ann Intern Med 2004;141:460-70.

4. Hudson LD, Milberg JA, Anardi D, Maunder RJ. Clinical risks for development of the acute respiratory distress syndrome. Am J Respir Crit Care Med 1995;151:293-301.

5. de Haro C, Martin-Loeches I, Torrents E, Artigas A. Acute respiratory distress syndrome: Prevention and early recognition. Ann Intensive Care 2013;3:11.

6. Spragg RG, Bernard GR, Checkley W, et al. Beyond mortality: Future clinical research in acute lung injury. Am J Respir Crit Care Med 2010;181:1121-7.

7. Erickson SE, Martin GS, Davis JL, Matthay MA, Eisner MD. Recent trends in acute lung injury mortality: 1996-2005. Crit Care Med 2009;37:1574-9.

8. Phua J, Badia JR, Adhikari NK, et al. Has mortality from acute respiratory distress syndrome decreased over time? A systematic review. Am J Respir Crit Care Med 2009;179:220-7.

9. Gattinoni L, Pesenti A, Avalli L, Rossi F, Bombino M. Pressure-volume curve of total respiratory system in acute respiratory failure. Computed tomographic scan study. Am Rev Respir Dis 1987;136:730-6.

10. Gattinoni L, Carlesso E, Caironi P. Stress and strain within the lung. Curr Opin Crit Care 2012;18,:42-7.

11. Gattinoni L, Caironi P. Refining ventilatory treatment for acute lung injury and acute respiratory distress syndrome. JAMA 2008;299:691-3.

12. Briel M, Meade M, Mercat A, et al. Higher vs lower positive end-expiratory pressure in patients with acute lung injury and acute respiratory distress syndrome: Systematic review and meta-analysis. JAMA 2010;303:865-73.

13. Gattinoni L, Pesenti A, Carlesso E. Body position changes redistribute lung computed-tomographic density in patients with acute respiratory failure: Impact and clinical fallout through the following 20 years. Intensive Care Med 2013;39:1909-15.

14. Froese AB, Bryan AC. Effects of anesthesia and paralysis on diaphragmatic mechanics in man. Anesthesiology 1974;41:242-55.

15. Gattinoni L, Tognoni G, Pesenti AP, et al. Effect of prone positioning on the survival of patients with acute respiratory failure. N Engl J Med 2001;345:568-73.

16. Taccone P, Pesenti A, Latini R, et al. Prone positioning in patients with moderate and severe acute respiratory distress syndrome: A randomized controlled trial. JAMA 2009;302:1977-84.

17. Mancebo J, Fernández R, Blanch L, et al. A multicenter trial of prolonged prone ventilation in severe acute respiratory distress syndrome. Am J Respir Crit Care Med 2006;173:1233-9.

18. Guérin C, Gaillard S, Lemasson S, et al. Effects of systematic prone positioning in hypoxemic acute respiratory failure: A randomized controlled trial. JAMA 2004;292:2379-87.

\section{SUMMARY AND RECOMMENDATIONS}

Persuasive physiological evidence and clinical trial data support the use of prone position ventilation in selected patients with moderate to severe ARDS $\left(\mathrm{PaO}_{2} / \mathrm{FiO}_{2}\right.$ ratios approaching $\left.100 \mathrm{mmHg}\right)$. For patients to benefit, selection using the criteria used in the PROSEVA trial and Table 2 may be helpful, and the use of long prone positioning sessions ( $12 \mathrm{~h}$ to $18 \mathrm{~h}$ per session) begun early in the course of ARDS (within $36 \mathrm{~h}$ of diagnosis) may be necessary. Prone positioning benefits oxygenation and improves mortality potentially through the mitigation of abnormal lung tissue strain and VALI. However, it is unclear whether the magnitude of benefit apparent in the PROSEVA trial will be replicated in centres with less expertise or different populations, and further research is warranted in this area.

19. Chan M-C, Hsu J-Y, Liu H-H, et al. Effects of prone position on inflammatory markers in patients with ARDS due to communityacquired pneumonia. J Formos Med Assoc 2007;106:708-16.

20. Fernandez R, Trenchs X, Klamburg J, et al. Prone positioning in acute respiratory distress syndrome: A multicenter randomized clinical trial. Intensive Care Med 2008;34:1487-91.

21. Chatte G, Sab J-M, Dubois J-M, Sirodot M, Gaussorgues P, Robert D. Prone position in mechanically ventilated patients with severe acute respiratory failure. Am J Respir Crit Care Med 1997;155:473-8.

22. Pelosi P, Tubiolo D, Mascheroni D, et al. Effects of the prone position on respiratory mechanics and gas exchange during acute lung injury. Am J Respir Crit Care Med 1998;157:387-93.

23. ARDSNetwork. Ventilation with lower tidal volumes as compared with traditional tidal volumes for acute lung injury and the acute respiratory distress syndrome. N Engl J Med 2000; 342:1301-8

24. Guérin C. Prone position. Curr Opin Crit Care 2014;20:92-7.

25. Mentzelopoulos SD, Roussos C, Zakynthinos SG. Prone position reduces lung stress and strain in severe acute respiratory distress syndrome. Eur Respir J 2005;25:534-44.

26. Papazian L, Gainnier M, Marin V, et al. Comparison of prone positioning and high-frequency oscillatory ventilation in patients with acute respiratory distress syndrome. Crit Care Med 2005;33:2162-71.

27. Galiatsou E, Kostanti E, Svarna E, et al. Prone position augments recruitment and prevents alveolar overinflation in acute lung injury. Am J Respir Crit Care Med 2006;174:187-97.

28. Broccard A, Shapiro RS, Schmitz LL, Adams AB, Nahum A, Marini JJ. Prone positioning attenuates and redistributes ventilatorinduced lung injury in dogs. Crit Care Med 2000;28:295-303.

29. Gattinoni L, Tognoni G. Effect of prone positioning on the survival of patients with acute respiratory failure. N Engl J Med 2001;345:568-73.

30. Guérin C, Reignier J, Richard J-C, et al. Prone positioning in severe acute respiratory distress syndrome. N Engl J Med 2013;368:2159-68.

31. Gattinoni L, Caironi P. Prone positioning: Beyond physiology. Anesthesiology 2010;6:1262-4.

32. Mure M, Martling CR, Lindahl SG. Dramatic effect on oxygenation in patients with severe acute lung insufficiency treated in the prone position. Crit Care Med 1997;25:1539-44.

33. Curley MA. Prone positioning of patients with acute respiratory distress syndrome: A systematic review. Am J Crit Care 1999;8:397-405.

34. Mure M, Glenny RW, Domino KB, Hlastala MP. Pulmonary gas exchange improves in the prone position with abdominal distension. Am J Respir Crit Care Med 1998;157:1785-90.

35. Nakos G, Tsangaris I, Kostanti E, et al. Effect of the prone position on patients with hydrostatic pulmonary edema compared with patients with acute respiratory distress syndrome and pulmonary fibrosis. Am J Respir Crit Care Med 2000;161:360-8

36. Lim CM, Kim EK, Lee JS, et al. Comparison of the response to the prone position between pulmonary and extrapulmonary acute respiratory distress syndrome. Intensive Care Med 2001;27:477-85. 


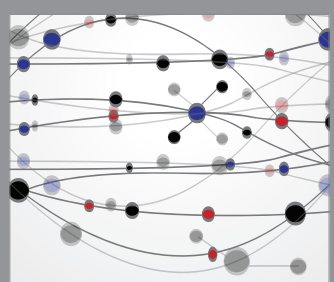

The Scientific World Journal
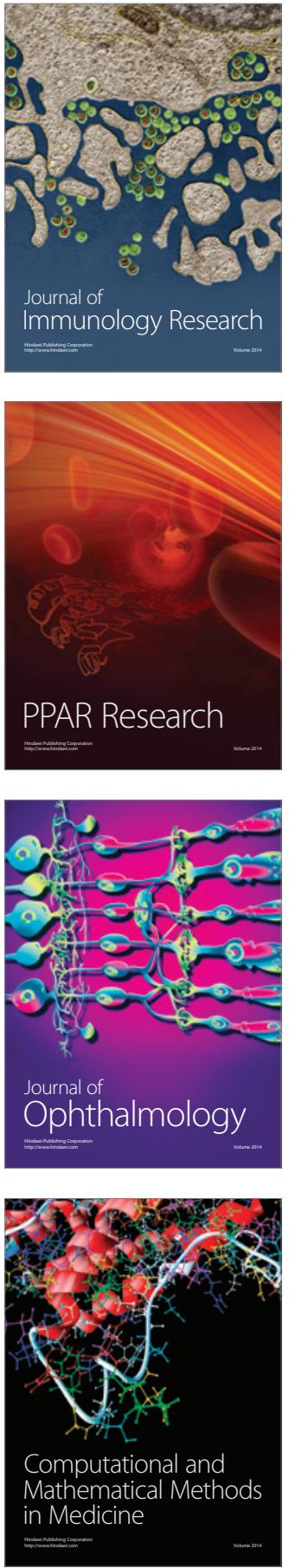

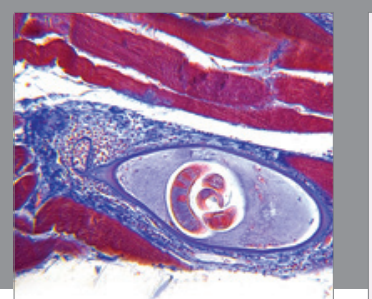

Gastroenterology Research and Practice

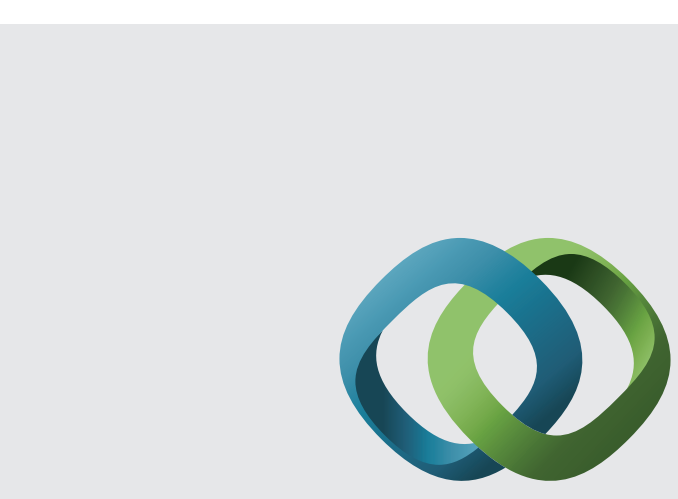

\section{Hindawi}

Submit your manuscripts at

http://www.hindawi.com
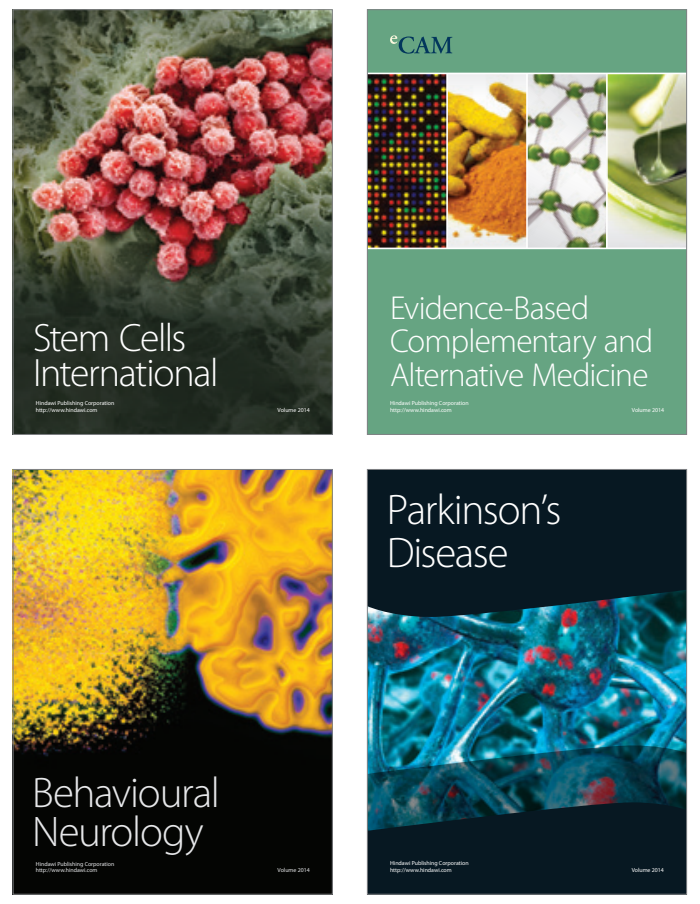
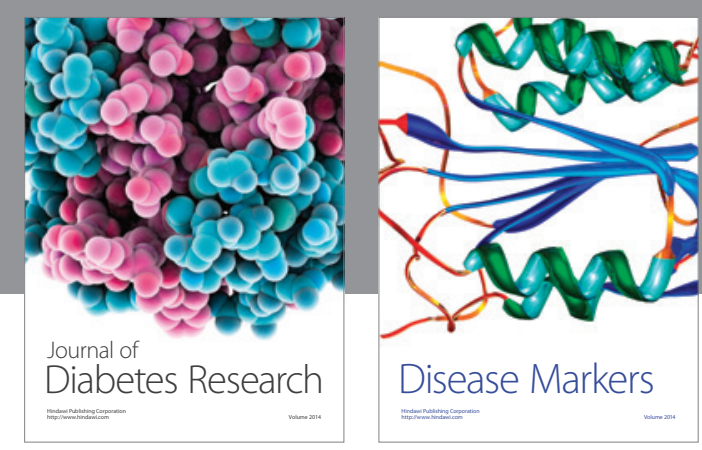

Disease Markers
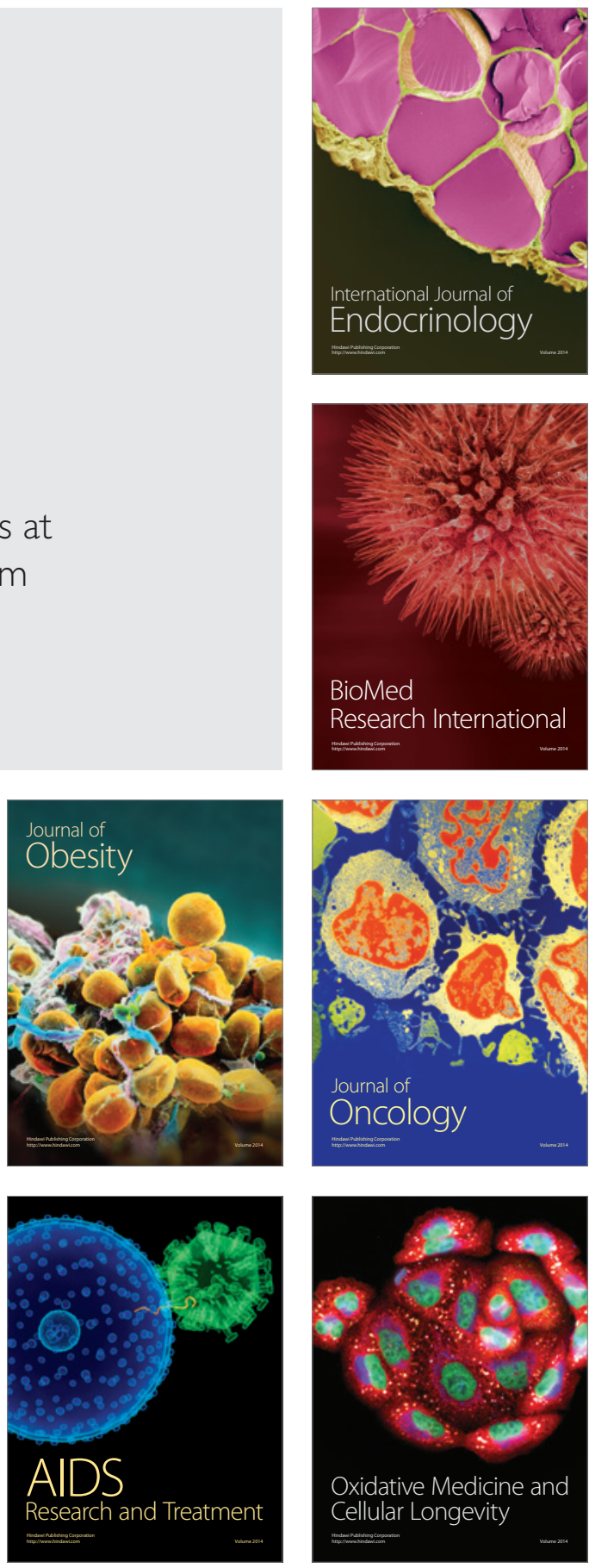